Article

\title{
The Sustainable Development of Social Media Contents: An Analysis of Concrete and Abstract Information on Cultural and Creative Institutions with "Artist" and "Ordinary People" Positioning
}

\author{
Yulin Chen \\ Department of Mass Communication, Tamkang University, New Taipei City 25137, Taiwan; \\ 143530@mail.tku.edu.tw; Tel.: +886-2-2621-5656
}

Received: 30 June 2019; Accepted: 29 July 2019; Published: 31 July 2019

check for updates

\begin{abstract}
The sustainability of social media is a common subject of study. With the emergence of cultural and creative industries, many studies have begun to explore the advantages and disadvantages of the integration of social media with cultural and creative industries. However, there remains a lack of research on the sustainability of cultural and creative social media. Therefore, the present study uses the example of a non-profit cultural and creative organization as its case. The use of social media content discovery technology explains the sustainable use of cultural and creative social media and how participation and interaction with cultural and creative brands are promoted from the perspective of artists or ordinary people. In addition, the analysis of concrete and abstract information explores how content orientation and brand perception impact emotions and behavior. We use social media content discovery technology to analyze 9529 image posts. The results show that for abstract themes, for example, art or design, people can be more easily guided by information with the help of images, which stimulate positive emotions, resulting in more actual engagement behavior, including posting and sharing. With respect to emotional responses, images with smiles are found to have a significant effect in guiding positive emotions, which are expressed through actions, such as active participation and feedback. By examining the meaning of the information in the images, we find that images with abstract themes have a good connection with the brand image. Although the information is less easily shown, it can guide significant outcomes that are positively correlated with the information. Therefore, strengthening brand image and content themes can effectively consolidate trust in brand content and the sustainable development of cultural and creative social media.
\end{abstract}

Keywords: cultural and creative industries; social media content exploration; abstract and concrete information; behavioral and emotional participation

\section{Introduction}

Social media content exploration is an analytical science that combines computer science, data mining, big data, machine learning, and social network analysis. It uses data and content to carry out various discussions. It is not only applicable to various brands of social content management but also has very important auxiliary effects for social content planning and decision making [1]. Since the participation of people is closely related to the social content, content exploration in social media has become one of the common research methods. For example, Kalampokis et al. (2013) used social media data to predict disease, stock market volatility [2], and election outcomes in different regions. Abrahams et al. (2013) used text exploration technology to examine the complaints about car brands on social platforms [3]. He et al. (2013) used text exploration to analyze the Facebook and Twitter content of three American pizza franchisers and understand public praise and Internet trends [4]. Currently, 
social media content exploration applications not only provide patterns to identify specific related topic information but can also be used to conduct qualitative and quantitative analyses to predict events with unstructured content.

Combining the instantaneity of social media with the rapid collection of content exploration has become the best approach to grasp the characteristics of people [5]. Social media content exploration mainly focuses on information collection for various websites and social platforms [6]. Therefore, exploration technology and tools are used to collect, share, explore, and visualize information [7]. So far, the commonly used exploration technologies include computer-based technology, such as retrieval and automatic or semi-automatic model construction [8]. Social media content can be explored by using text data and text exploration models to determine specific patterns and relationships of content. Different types of content, such as image, video, multimedia, audio, and other information and data, can be used for mining and testing the data content of these unstructured texts [9].

In recent years, research into social media content has been growing rapidly. Whether it is semantic analysis based on the textual content of Twitter or Pinterest, or image, textual, and video analyses of Facebook or Instagram, the relationships between the contents of different communities and user needs are being explored. For example, users who actively use Facebook and Twitter tend to be the ones in the community who execute the most likes or follows [10]. An investigation of users in a community has found via association that their motivations for use are often interactively influencing the demand for posts. For example, an investigation of image posts has shown that users display two different kinds of feelings: sentimental images and cognitive images. Sentimental images are images that easily stimulate sentiments or emotions in users [11]. Cognitive images often use non-textual descriptions such as portraits or images to reduce users' barriers to posts, which has become a common method for communities to expand into different populations [12]

Based on many previous studies and findings, online images and content are the best way to create image. Either the text or the image is constantly creating and transferring information [13]. Therefore, social media has an irreplaceable value for image promotion, and often plays a key role in image sustainable development. Image information is helpful for not only forming the image but also understanding the perception and ideas of people, thereby facilitating the expression of appropriate images and themes from the perspective of people [14]. The positioning of content image is indeed beneficial for brand image formation and can reduce excessive complexity or contradiction when communicating with people [15]; it can even use positive elements to convey exclusive brand characteristics and attributes [16]. Therefore, considering the industry's high reliance on social media platforms and the trend toward social media content discovery technology, the present study focuses on cultural and creative industries and explores the future sustainable development of cultural and creative social media.

In contrast to the simple business perspective of enterprises, the cultural industry is characterized by complexity and contradictions. Holden (2006) asserted that, to be representative of culture and art, any legitimate cultural entity must not only be creative but also have a symbolic meaning representing certain symbols or images [17]. The meaning of the term "culture" can be reflected in social experience, art exhibitions, or everyday practice [18]. Many cultural and creative industries are established in a similar way: the development of brands creates a shared or homogeneous cultural experience among a group of people [19], producing similar beliefs, traditions, values [20], and so on. Of these, cultural and creative products can take the form of symbols or text [21]. Therefore, cultural and creative industries are seen as a product of experience and art. People can not only appreciate cultural creativity but also create culturally unique spiritual symbols together with the brand. Using appropriate content to communicate with groups of people can be referred to as cultural and creative marketing [22]. It can achieve the ultimate objective of establishing communication between art and groups of people. In this way, the sustainable development of cultural and creative industries can provide more diverse cultural values [23]. 
With the global emergence of creative industries [24], the creative industries in Asian countries, including Taiwan, largely emerged from the blueprint of a British Labour Party report in 1998 on cultural and creative industries. This blueprint was quickly passed from the United Kingdom to Taiwan; in 2008, the Taiwan government proposed the "Challenge 2008 National Development Plan." Cultural and creative industries involve the Ministry of Economic Affairs, Council for Cultural Affairs, Ministry of Education, and Council for Economic Planning and Development. The Ministry of Economic Affairs set up a working group to integrate these responsibilities, and the government has systematically developed cultural and creative industries from the top down. Of these, two cultural and creative parks have the largest scale and most unique characteristics. Located in Taipei, the Huashan 1914 Creative Park is a historical and cultural property. Since 1999, it has become a venue for cultural events, such as art exhibitions and music performances, and has the unique characteristics of an "artists' cultural and creative organization". The Pier-2 Art Center is an art center located in Kaohsiung, creating an international art platform through the application of avant-garde, experimental, and innovative concepts. The Pier-2 Art Center is operated by the Bureau of Cultural Affairs of the Kaohsiung City Government. It is owned by the Kaohsiung City Bureau of Cultural Affairs and the Kaohsiung City Cultural and Administrative Corporation. It provides a multi-faceted cultural and creative exhibition and is characterized as an "ordinary people's cultural and creative organization".

In this study, we look at the social media platforms of these two representative cultural and creative organizations. First, how can cultural and creative social media expand the sustainability of its content? Second, based on different content or exhibition needs, for example, the different characteristics of cultural and creative industries for artists and ordinary people, how can the sustainability of the content be used to increase the emotional and behavioral engagement of social media users? Finally, is it possible to integrate existing social media content exploration technology to provide recommendations pertaining to the management and development of sustainable cultural and creative social media?

In addition, the present study understands that online images and content are the best way to generate the creative image of brand culture [25]. We divide the model proposed by Aaker et al. into functional images and symbolic images according to the features and positioning obtained during image exploration. Symbolic images are mainly abstract and thematic images [26], while functional images mainly represent specific objects [27]. This allows us to explore whether concrete factors and abstract factors in image posts have a positive influence on emotions and behaviors.

However, most studies on social media management strategies have purely focused on the analysis of commercial brands, whereas very few have discussed brands of a noncommercial nature. Therefore, this study attempts to focus on a different type of brand positioning and take nonprofit cultural and creative brands as examples. This study discusses how the images of cultural and creative brands influence the relationship between information factors and emotional factors. In the strategies applied to social content development, information can be emphasized with images, and some topics can be analyzed, such as the kind of negative emotional and behavioral influence that can be exerted when the positioning of the content is different from people's cognition of the brand. To verify the findings of the analyses in this study, the content sustainable development of social media of cultural and creative industries is first considered by taking the Huashan 1914 Creative Park in Taiwan and the Pier-2 Art Center as examples to demonstrate the difference in cultural and creative brands between "artist" positioning and "ordinary people" positioning. Subsequently, the study explains how content image benefits content sustainable development differently and influences people's cognition and emotions. In addition, this study focuses on social content in the form of images and discusses whether the images can lead to people's cognition of brands; these forms can be applied by future cultural and creative industries and relevant institutes in their social media marketing and brand positioning. The purpose of this study is to explore the conclusions according to the real examples and master the methods and concepts of information management for different cultural and creative industries.

The study is organized as follows: Section 2 briefly summarizes the relevant literatures and theories of content images and the quality of information at the current stage; Section 3 proposes the 
relevant hypotheses on how images and text related to cultural and creative brands with different display purposes influence people's participation in the homepages as followers, and then analyzes how different factors influence people's emotions and behaviors; Section 4 focuses on the operating methods in the study; Section 5 analyzes the data; Section 6 discusses the conclusions and explains how to use this model to conduct social content management and content sustainable development planning.

\section{Theoretical Background}

Research on social media posts has grown rapidly in recent years in terms of the text content analysis based on semantics, including research on the characteristics of images, text, or video and analyses of the impact of social media text, images, or video on the responses of people [28]. In addition, some studies have further discussed various types of posts and media elements, such as the elements in images or videos that have a positive impact on people. All of these empirical studies have validated that information can shape the experience environment and enable interaction between different social media and people [29]. Since information can be used to induce people and help them create associations, the interaction between people's emotional state and information content must be interrelated and predictable beforehand. For example, Zhang (2014) believed that information triggers emotional responses and drives people to generate cognition, emotion, and evaluation [30]. In terms of social content, it is often found to use information packaging to arouse emotional support from people, so as to strengthen brand power and provide different emotional guidance, such as experience, care, understanding, and sympathy [31].

The content image refers to the image of a specific content or object [32], which includes various elements, such as the cognition, perception, and emotion of the content, especially the overall image presented in brand perception and emotion. It is often formed by various sources of information, such as online pictures of the content. According to different media types, the online content can be divided into online text, online image, online video, and other media types. Almost all brands can use social media to launch a commercial social media strategy and build a model to measure the social characteristics of people [33]. Stieglitz et al. (2014) suggested using people analysis to support the formation of deep relationship marketing [34]. This can be interpreted as using clear content positioning to attract more people with the same attributes [35]. In fact, the participation of the brand is closely related to the positioning of the content image, which mainly depends on many internal and external factors [36]. The content image depends on people's intention, while the intention depends on preferences, which are in turn affected by emotions; for example, positive and negative images can result in differences in participation intentions and attitudes.

Woodside and Lysonski (1989) further interpreted the relationship between the content image and intention [37]. They proposed three inspection criteria for a content image, namely, the general attribute, psychological function, and relevance level. General attributes refer to the general images of the content and the cognition of individual attributes. Psychological functions are the psychological characteristics of the content image. The relevance level refers to all general images and related images, showing the relationship between the content image and behavior intention.

Among them, abstract images are represented by general attributes and psychological functions, whereas concrete images are represented by the symbols of relevant images.

Both concrete and abstract images in the content image can affect people's cognition, emotion, and intention toward a brand. Cognition includes knowledge and belief; emotion generally refers to aspects such as emotions, feelings, and attachment. Therefore, in addition to cognitive and emotional assessments, the assessment of behavioral intentions is also necessary [38]. Among the related studies, Gartner (1994) paid special attention to the formation process of the image and discussed the influence of different types of information on people's cognition and emotion [39]. It was found that, irrespective of the different images, the implementation of positive information can produce more positive image promotion and participation willingness. Images are mostly affected by individual psychological attitudes, representing personal knowledge, beliefs, feelings, and feedback for the content. Although 
Gartner (1994) argued that the content image depends on the causal relationship between cognition and emotion, he emphasized the possibility that personal feelings have an impact on the content image. Gallarza et al. (2002) pointed out that since the elements of content image are very complex, either due to time or space [40], they are constantly changing by subjective factors or produce more meanings through social interactions [41].

Many studies in the past have evaluated information quality and information services. Huang et al. (2010) asserted that information quality can be used as a criterion for judging its suitability for people [42]. Kahn et al. (2002) believed that information quality must possess the characteristics required to meet the expectations of people [43]. In addition, there are some reviews of information quality from people's perspective, such as the framework of information quality proposed by Wang (1996), according to which information quality should be divided from people's perspective [44], instead of the conventional systematic perspective, into four analytical dimensions: internal level, context level, representative level, and accessibility level. Agarwal and Karahanna (2000) extended the details of each dimension of information quality [45]. In addition, Kahn et al. (2002) divided information quality into two dimensions: concrete and abstract. They examined different aspects of products, services, and performance, and ultimately obtained four representative evaluation criteria: robustness, usefulness, reliability, and availability (Table 1).

Table 1. Related researches of information quality.

\begin{tabular}{|c|c|c|}
\hline $\begin{array}{c}\text { Information Related } \\
\text { Researches }\end{array}$ & Research Topics & Researcher(s) \\
\hline \multirow{5}{*}{$\begin{array}{l}\text { Information quality and } \\
\text { information services }\end{array}$} & Information quality criterion & Huang, Basu, and Hsu, 2010 \\
\hline & Information quality characteristics & Kahn, Strong, and Wang, 2002 \\
\hline & $\begin{array}{l}\text { Information quality dimensions: internal } \\
\text { level, context level, representative level, and } \\
\text { accessibility level }\end{array}$ & Wang, 1996 \\
\hline & Information quality details & Agarwal and Karahanna, 2000 \\
\hline & $\begin{array}{l}\text { Information quality dimensions: robustness, } \\
\text { usefulness, reliability, and availability }\end{array}$ & Kahn, Strong, 2002 \\
\hline \multirow{4}{*}{$\begin{array}{l}\text { Information quality } \\
\text { indicators }\end{array}$} & Context quality indicators & Klein, 2002 \\
\hline & Information retrieval indicators & Knight and Burn, 2005 \\
\hline & Social media information quality indicators & Agarwal and Karahanna, 2000 \\
\hline & $\begin{array}{l}\text { Social media information quality } \\
\text { classification indicators } \\
\text { Satisfaction is related to information }\end{array}$ & $\begin{array}{l}\text { Emamjome, Rabaa'i, Gable, and } \\
\text { Bandara, } 2013 \\
\text { Prayag, } 2009\end{array}$ \\
\hline
\end{tabular}

In addition, similar concrete criterion indicators include the context quality indicators of Internet information [46], information retrieval indicators [47], social media information quality indicators [45], and social media information quality classification indicators [48]. In addition, the interaction between perceived quality and people in the abstract dimension is also inspected [49]. Lee et al. (2015) found that the abstract image and perceived quality are mutually related [50]. Satisfaction is related to information [51], and intention is related to information. According to the relationship between information quality and intention, Tseng et al. (2015) divided information quality into three stages [52]. The first stage begins with Gunn's guidance stage, which mainly includes the content image of induction and the adjustment to the induction [53]. This stage is mainly represented by concrete symbols. In the second stage, the concept of people perception is introduced [54], which includes cognition, emotion, and intention. It is guided by multi-level thematic images and has subsequently become the most common theoretical framework for content images. The third stage links the content image and brand positioning to provide a holistic consideration and integrated evaluation. This study integrates 
Wang's information quality framework [44], referring to different evaluation criteria, such as Internet information [46], e-commerce information [43], and social media information characteristics [48], and re-establishes the framework with special attention to the relevant factors in social content. Paying special attention to the characteristics of image information in community content (both concrete and abstract), analysis and evaluation are conducted for the cognitions, sentiments, and behaviors that may be triggered by these characteristics.

\section{Research Model and Hypothesis}

\subsection{Abstract Factors with An Impact on Emotional and Behavioral Participation}

Brands can also establish distinct social positioning, such as by the classification of rational and emotional images, which not only helps to increase loyalty among people but also is very useful in tackling competitors. Certainly, good content sustainable development cannot automatically work for the brands simply by creating social media. To benefit from social media, brands must enhance both their own public image and people's trust [55]. They believed that it is important for a brand to send information that matches its own positioning to build a social image, which can effectively establish a consistent position or relationship and simultaneously strengthen brand awareness [56].

Content image is regarded as the process of people's recognition of the content. It constantly uses the unique value of the content to connect people's brand impressions and generate content beliefs and associations; it even uses perceptions to build a good feeling toward the content. According to its characteristics and positioning, the content can be divided into a functional image, an experiential image, and a symbolic image. A symbolic image is abstract and thematic, while a functional image is mainly based on concrete icons [27]. For example, they evaluated a content image on the basis of four factors: perceived quality, perceived value, uniqueness, and content intention. They found that perceived quality represents a concrete image and perception, whereas perceived value represents the perception in abstract consciousness. Therefore, different incentives directly or indirectly affect people's attitudes toward social media, reasons for using social media, different experiences, and different attitudes toward social participation [57].

The purpose of this study is to understand the information packaging and positioning of the culture-creativity image in order to make the image attractive to people. Furthermore, cultural and creative brands are often concerned with the setting by the setting of the content image. Therefore, this study uses two cultural and creative brands with "artist" positioning and "ordinary people" positioning to analyze how the content images are related to the user emotional and behavioral response. Symbolic images tend to be abstract and make use of themes or sentiments and others to convey message content, such as design, art, and branding. Functional images mainly use specific messages and make statements with clear signs or objects, such as products, illustrations, and buildings [26,27]. This study emphasizes the quality of image information to discuss the abstract factors further (for example, design, art, and brand, etc.). The basic hypotheses are as follows (Figure 1):

Hypothesis 1 (H1). The abstract factor images of the "artist" field brands have a significant difference with the user behavioral and emotional response.

Hypothesis 1a (H1a). The abstract factor images of the "artist" field brands have a significant difference with the user emotional response.

Hypothesis $1 \mathbf{b}$ (H1b). The abstract factor images of the "artist" field brands have a significant difference with the user behavioral response.

Hypothesis H2 (H2). The abstract factor images of the "ordinary people" field brands have a significant difference with the user behavioral and emotional response. 
Hypothesis H2a (H2a). The abstract factor images of the "ordinary people" field brands have a significant difference with the user emotional response.

Hypothesis H2b (H2b). The abstract factor images of the "ordinary people" field brands have a significant difference with the user behavioral response.

\section{Abstract and Concrete Factor}

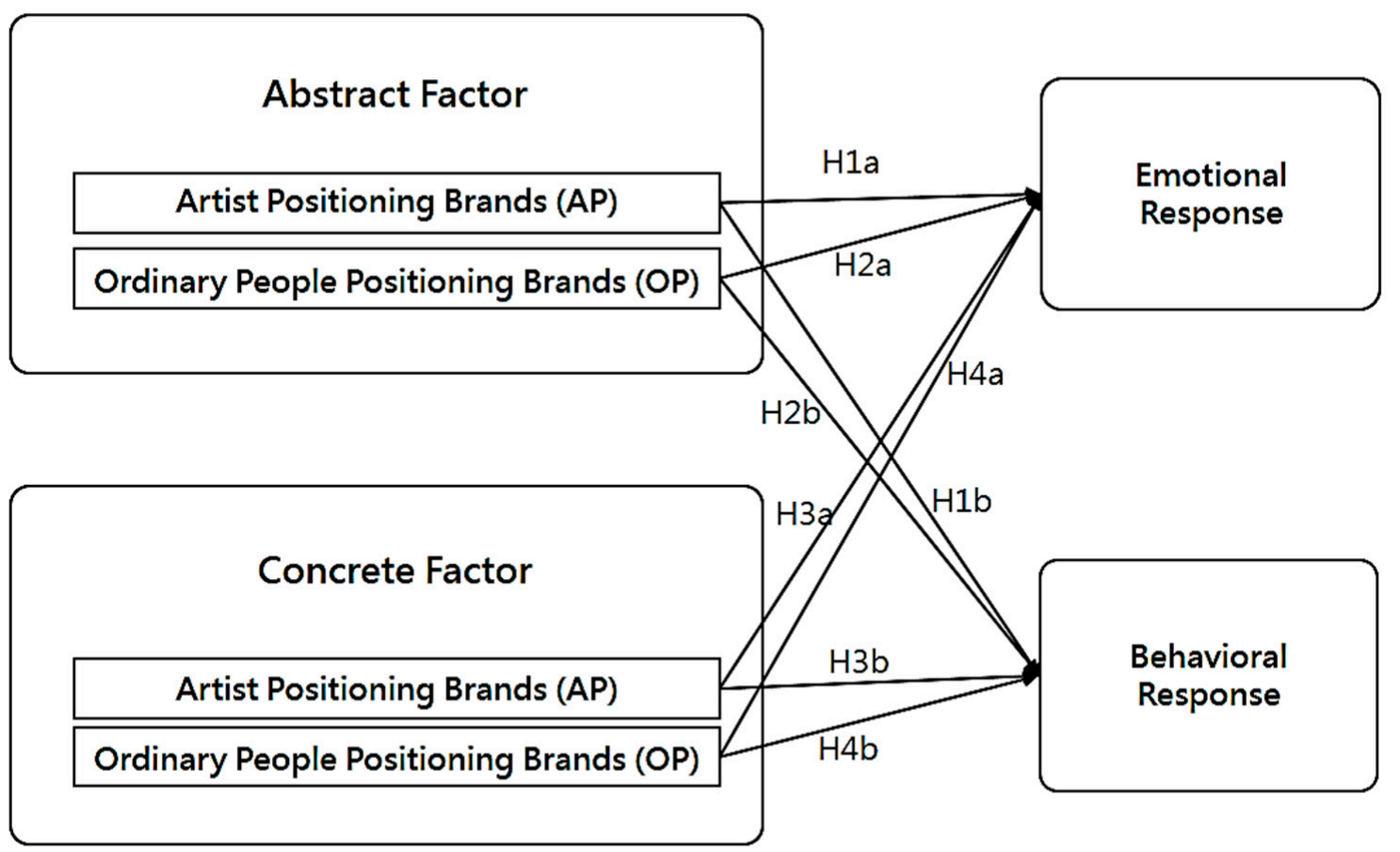

Artist Positioning Brands (HIa, Hlb, H3a, H3b) ; Ordinary People Positioning Brands (H2a, H2b, H4a, H4b).

Figure 1. Extended research model.

\subsection{Concrete Factors with An Impact on Emotional and Behavioral Participation}

Psychological studies have generally claimed that emotions can affect the degree of people's identity when people are reading information [58]; the most common occurrence is the guidance of positive and negative emotions [59]. Human emotions are evoked through specific stimuli [60] because emotions have different evaluations from the information. Schwarz and Clore (2003) found that emotions can enhance different levels of information memory [61], judgment, and evaluation; indeed, positive emotions can enhance positive attitudes and persuasion toward the brand. When people are in a happy mood, the evaluation of information will be more positive [62]. Although most of the literature has focused on exploring positive factors, some studies have found that negative emotions are similarly correlated. It has been further demonstrated that the emotional state may be due to a temporary personality produced by a particular environment, which has a behavioral or cognitive impact on a particular object [63]. The content image refers to people's image of a product or service [64]. Therefore, the content image mainly comes from people's self-discovery or self-construction, which then extends to the concrete (icon) image [26]. By setting specific information (text or image) characteristics, a linked theme or a symbolic feature can be generated. Therefore, this study emphasizes the quality of image information to discuss the concrete image further (for example, products, illustrations, and exhibitions) and presents the following hypotheses related to the reaction of people's emotions and intentions: 
Hypothesis 3 (H3). The concrete factor images of the "artist" field brands have a significant difference with the user behavioral and emotional response.

Hypothesis 3a (H3a). The concrete factor images of the "artist" field brands have a significant difference with the user emotional response.

Hypothesis $3 \mathbf{b}(\mathbf{H} 3 \mathbf{b})$. The concrete factor images of the "artist" field brands have a significant difference with the user behavioral response.

Hypothesis 4 (H4). The concrete factor images of the "ordinary people" field brands have a significant difference with the user behavioral and emotional response.

Hypothesis 4a (H4a). The concrete factor images of the "ordinary people" field brands have a significant difference with the user emotional response.

Hypothesis $4 \mathrm{~b}(\mathbf{H} 4 \mathrm{~b})$. The concrete factor images of the "ordinary people" field brands have a significant difference with the user behavioral response.

\section{Research Methodology}

\subsection{Theoretical Foundation}

This study verifies the emotional and behavioral data of social media users by means of the concrete and abstract factors in content image, with reference to abstract and concrete information theory, cognitive, emotional and behavioral theory, and online participation theory.

A symbolic image is abstract and thematic, while a functional image is mainly based on concrete icons [26]. Both concrete and abstract images in the content image can affect people's cognition, emotion, and intention toward a brand. Cognition includes knowledge and belief; emotion generally refers to aspects such as emotions, feelings, and attachment [39]. The concept of people perception [54] includes cognition, emotion, and intention. It is guided by multi-level thematic images and has subsequently become the most common theoretical framework for content images. Most of the information on Facebook pages is presented in the form of text, photos, videos, and links. Measures of online participation behavior include Likes, Comments, and Shares. Emotions include Love, Haha, Wow, Sorry, and Anger [65]. User responses have always been considered as a valid reference for social media operations and related user behaviors $[31,66,67]$. For example, clickthrough rates are often seen as a type of active user engagement, and data such as interaction rates and views are also commonly used [68]. This study is based on conditions in Facebook's terms of service, allowing application designers to observe interactions and obtain post data and content for research purposes [69-71]. In addition, to ensure the accuracy of the data, we use the Facebook graphics application program to collect daily posts [72], including the content of each post, the type of post, the posting time, the number of Likes, the number of Shares, and the number of Comments for each article, and extract the information for classification. 


\subsection{Image Analysis Method}

This study focused on image content by using techniques for exploring and filtering social media content. First, the API of the community software was used to extract relevant content and data for Facebook and next all the collected data were subjected to screening and collation. Through image analysis techniques provided by Google Cloud sVision, the images were subjected to face detection, brand tag detection, network content detection, textual recognition detection, etc. Automatic determination technology with machine learning was used to detect figurative and abstract elements in the images, such as faces, words, items, and brand logos. Through machine learning, classification was conducted automatically. The aim was to use artificial intelligence to integrate image analysis with machine learning and perform quantitative analysis on community image elements.

\subsection{Sample Introduction}

In the display of cultural and creative contents, for images possessing very different themes, not only possessing the brand imagery of "artists" and "ordinary people", but also the performance of community content, it is necessary to actively conduct packaging and adjustment according to user characteristics. Therefore, as a reference for cultural and creative community contents, this study is significant. The Huashan 1914 Creative Park and the Pier-2 Art Center are selected to represent the two cultural and creative brands with "artist" positioning and "ordinary people" positioning.

The pre-test phase covered the year of 2018. As the number of posts was less than 1000, the results for both emotions and behaviors were not significant. Therefore, the data was re-filtered for a posting frequency of five times in a single week. Finally, all the posts from January 1st, 2011, to December 31st, 2018, were collected, for a total of 11,176 posts. Of the posts, 9529 have photo content. Of the interactions, there are 2,539,514 Likes, 35,251 Comments, and 91,219 Shares. Of the emotional responses, there are 9,017 for Love, 5,449 for Haha, 4,356 for Wow, 715 for Sorry, and 218 for Anger (Table 2). Of the abstract factor, there are 2,355 for Design, 1,682 for Art, 1,344 for Brands, and of the concrete factor, 1,584 for Product, 816 for Graphic, and 1,166 for House (Table 3). 
Table 2. Total posts.

\begin{tabular}{|c|c|c|c|c|c|c|c|c|c|c|}
\hline Posts & Likes & Comments & Shares & $\begin{array}{l}\text { Behavioral } \\
\text { Participation }\end{array}$ & Love & Haha & Wow & Sorry & Anger & $\begin{array}{c}\text { Emotional } \\
\text { Participation }\end{array}$ \\
\hline $\begin{array}{l}\text { Artist positioning brands } \\
\qquad(\mathrm{n}=4053)\end{array}$ & 343,965 & 7802 & 22,632 & 374,399 & 3161 & 1312 & 1323 & 95 & 25 & 5916 \\
\hline $\begin{array}{l}\text { Ordinary people positioning } \\
\text { brands }(\mathrm{n}=5476)\end{array}$ & $2,195,549$ & 27,449 & 68,587 & $2,291,585$ & 5856 & 4137 & 3033 & 620 & 193 & 13,839 \\
\hline Sum $(n=9529)$ & $2,539,514$ & 35,251 & 91,219 & $2,665,984$ & 9017 & 5449 & 4356 & 715 & 218 & 19,755 \\
\hline
\end{tabular}

Table 3. Total number of factors.

\begin{tabular}{|c|c|c|c|c|c|c|c|c|}
\hline Posts & Design & Art & Brands & $\begin{array}{c}\text { Abstract Factor } \\
\text { (AF) }\end{array}$ & Product & Graphic & House & $\begin{array}{l}\text { Concrete Factor } \\
\text { (CF) }\end{array}$ \\
\hline $\begin{array}{l}\text { Artist positioning brands } \\
\qquad(\mathrm{n}=4053)\end{array}$ & 961 & 538 & 585 & 2084 & 673 & 321 & 381 & 1375 \\
\hline $\begin{array}{l}\text { Ordinary people positioning } \\
\text { brands }(\mathrm{n}=5476)\end{array}$ & 1394 & 1144 & 759 & 3297 & 911 & 495 & 785 & 2191 \\
\hline Sum $(n=9529)$ & 2355 & 1682 & 1344 & 5381 & 1584 & 816 & 1166 & 3566 \\
\hline
\end{tabular}




\section{Data Analyses and Results}

\subsection{Reliability and Validity}

Using SPSS software, we analyze the Cronbach $\alpha$ coefficient to verify the reliability and internal consistency of each scale in the sample. The results of the reliability analysis show that the Cronbach $\alpha$ for the abstract factor component and concrete factor component is 0.710 and 0.706 , respectively. The included items are also correlated. This indicates that it can be used to measure the sustainability of social media cultural and creative content and that all of the items are closely correlated with the total.

In this study, the Cronbach's $\alpha$ is 0.701 and the Kaiser-Meyer-Olkin (KMO) value is 0.696. The factor load actually meets the basic criteria of being equal to or higher than 0.6 and has convergent and discriminant validity. The data were subjected to statistical analysis to determine the correlations of each independent variable, via linear regression analysis and correlation analysis, in order to confirm the research structure and hypothesis.

\subsection{Hypothesis Testing}

First, we test Hypothesis 1 to determine whether the abstract factor images of the "artist" field brands have an impact on the user behavioral and emotional response. Of these, H1a, the abstract factor images of the "artist" field brands have a significant difference with the user emotional response, is not supported. However, H1b has impacts on the emotional response of social media users, is supported.

Second, we test Hypothesis 2 to determine whether the abstract factor images of the "ordinary people" field brands have a significant difference with the user behavioral and emotional response. $\mathrm{H} 2 \mathrm{a}$ and $\mathrm{H} 2 \mathrm{~b}$, are found to be not supported; that is, the abstract factor images of the "ordinary people" field brands have a significant difference with the user emotional response.

Next, we test Hypothesis 3 to determine whether the concrete factor images of the "artist" field brands have a significant difference with the user behavioral and emotional response. The results show that $\mathrm{H} 3 \mathrm{a}$ and $\mathrm{H} 3 \mathrm{~b}$ are supported; that is, that the concrete factor images of the "artist" field brands have a significant difference with the user emotional response.

Finally, we test Hypothesis 4 to determine whether the concrete factor images of the "ordinary people" field brands have a significant difference with the user behavioral and emotional response. $\mathrm{H} 4 \mathrm{a}$ and $\mathrm{H} 4 \mathrm{~b}$ are supported; that is, that the concrete factor images of the "ordinary people" field brands have a significant difference with the user emotional response (Table 4).

Table 4. Findings.

\begin{tabular}{clc}
\hline ID & \multicolumn{1}{c}{ Hypothesis } & Verdict \\
\hline $\mathrm{H} 1$ & $\begin{array}{l}\text { The abstract factor images of the "artist" field brands have an impact on } \\
\text { the user behavioral and emotional response. }\end{array}$ & Partial supported \\
\hline $\mathrm{H} 1 \mathrm{a}$ & $\begin{array}{l}\text { The abstract factor images of the "artist" field brands have a significant } \\
\text { difference with the user emotional response. }\end{array}$ & Not supported \\
\hline $\mathrm{H} 1 \mathrm{~b}$ & $\begin{array}{l}\text { The abstract factor images of the "artist" field brands have a significant } \\
\text { difference with the user behavioral response. }\end{array}$ & Supported \\
\hline $\mathrm{H} 2$ & $\begin{array}{l}\text { The abstract factor images of the "ordinary people" field brands have a } \\
\text { significant difference with the user behavioral and emotional response. }\end{array}$ & Not supported \\
\hline $\mathrm{H} 2 \mathrm{a}$ & $\begin{array}{l}\text { The abstract factor images of the "ordinary people" field brands have a } \\
\text { significant difference with the user emotional response. }\end{array}$ & Not supported \\
\hline $\mathrm{H} 2 \mathrm{~b}$ & $\begin{array}{l}\text { The abstract factor images of the "ordinary people" field brands have a } \\
\text { significant difference with the user behavioral response. }\end{array}$ & Not supported \\
\hline $\mathrm{H} 3$ & $\begin{array}{l}\text { The concrete factor images of the "artist" field brands have a significant } \\
\text { difference with the user behavioral and emotional response. }\end{array}$ & Supported \\
\hline
\end{tabular}


Table 4. Cont.

\begin{tabular}{clc}
\hline ID & \multicolumn{1}{c}{ Hypothesis } & Verdict \\
\hline H3a & $\begin{array}{l}\text { The concrete factor images of the “artist” field brands have a significant } \\
\text { difference with the user emotional response. }\end{array}$ & Supported \\
\hline $\mathrm{H} 3 \mathrm{~b}$ & $\begin{array}{l}\text { The concrete factor images of the "artist" field brands have a significant } \\
\text { difference with the user behavioral response. }\end{array}$ & Supported \\
\hline $\mathrm{H} 4$ & $\begin{array}{l}\text { The concrete factor images of the "ordinary people" field brands have a } \\
\text { significant difference with the user behavioral and emotional response. }\end{array}$ & Supported \\
\hline H4c & $\begin{array}{l}\text { The concrete factor images of the “ordinary people" field brands have a } \\
\text { significant difference with the user emotional response. }\end{array}$ & Supported \\
\hline H4d & $\begin{array}{l}\text { The concrete factor images of the “ordinary people" field brands have a } \\
\text { significant difference with the user behavioral response. }\end{array}$ & Supported \\
\hline
\end{tabular}

\section{Discussion and Factors}

\subsection{Discussion of Results}

The verification results are explained below (Figure 2). First, we discuss the results of testing Hypothesis 1. The abstract factor images of the "artist" field brands have an impact on the people behavioral and emotional response. For the people emotional response, the "artist" field brands have values of $\beta=-0.012, t=-0.822$, and the people behavioral response has values of $\beta=-0.078$, $\mathrm{t}=-5.003$, and $p<0.001$.

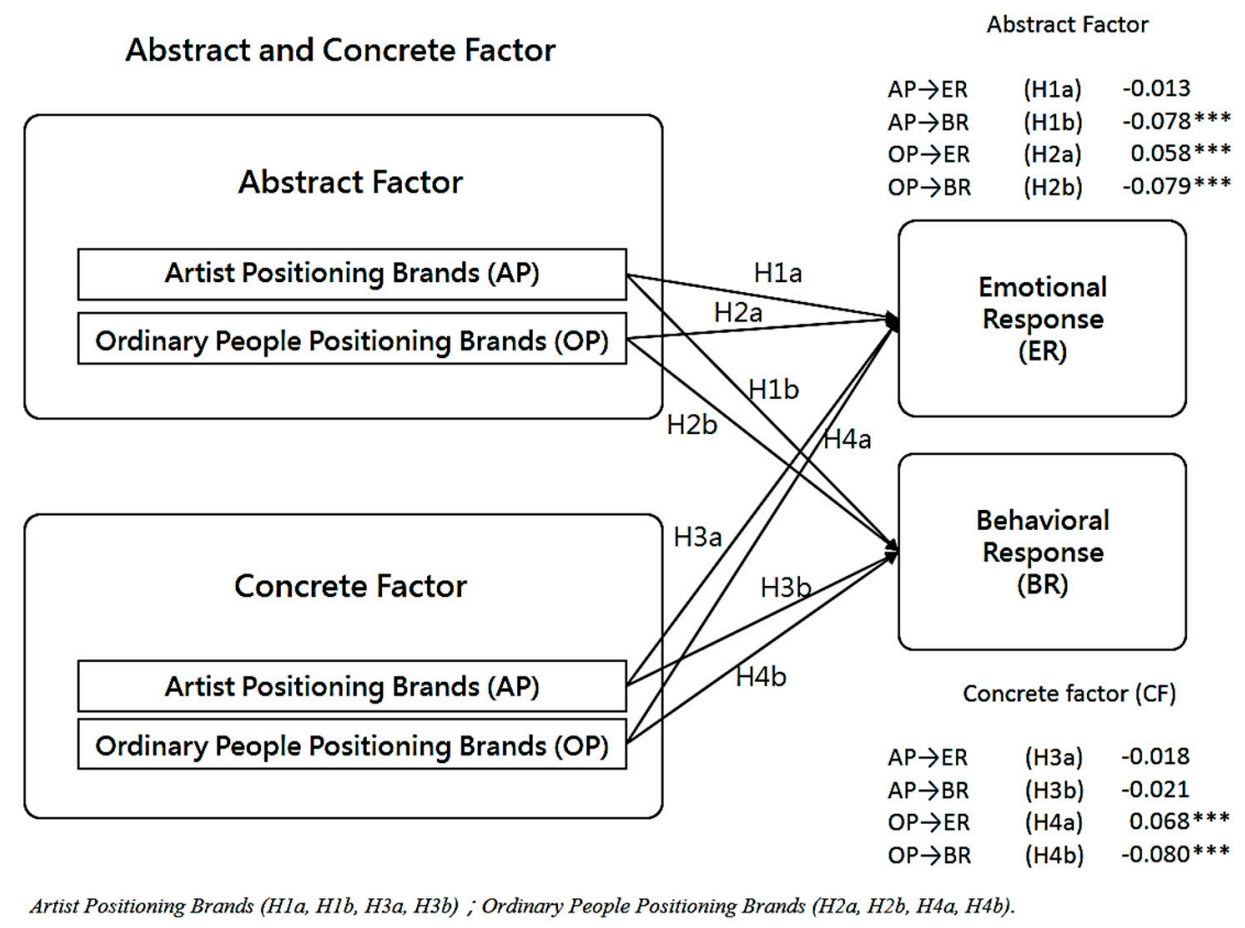

Figure 2. Model results.

Second, we discuss the results of testing Hypothesis 2. The abstract factor images of the "ordinary people" field brands have a significant difference with the people behavioral and emotional response. For the people emotional response, the "ordinary people" field brands have values of $\beta=0.057$, $\mathrm{t}=4.292$, and $p<0.001$, and the people behavioral response has values of $\beta=-0.079, \mathrm{t}=-5.895$, and $p<0.001$. 
Next, we discuss the results of testing Hypothesis 3. The concrete factor images of the "artist" field brands have a significant difference with the people behavioral and emotional response. For the people emotional response, the "artist" field brands have values of $\beta=-0.018, t=-1.164$, and the people behavioral response has values of $\beta=-0.020, t=-1.321$.

Finally, we discuss the results of testing Hypothesis 4 . The concrete factor images of the "ordinary people" field brands have a significant difference with the people behavioral and emotional response. In terms of the people emotional response, the concrete factor images of the "ordinary people" field brands have values of $\beta=0.068, t=5.057$, and $p<0.001$, and the people behavioral response has values of $\beta=-0.080, \mathrm{t}=-5.942$, and $p<0.001$.

\subsection{Theoretical Factors and Limitations and Future Research}

Currently, few studies have focused on nonprofit community brands, and even fewer have examined the effectiveness of the content sustainable development launched by cultural institutions. Therefore, this study specially focuses on the discussion of the value of social content sustainable development for cultural and creative brands as well as the differences in the content and positioning of cultural and creative brands. In addition, using social data, the execution methods of content sustainable development to reach an agreement with people's information perception are also discussed. Moreover, it is important to understand how people participate in social media according to different incentives and how they have different attitudes toward different target images; this is the main focus of this study. The specific results are summarized below (Table A1, Table A2, Table A3).

First, when exploring how cultural and creative social media can expand the sustainability of its content, we found that the content image does have sustainable use characteristics. In addition, we verified that content image can successfully connect the perception of specific images and abstract consciousness.

In terms of the abstract themes, such as arts or designs, with the assistance of pictures, people can more easily feel the guidance of information and stimulation of positive emotions, which generate more practical behavior of participation, including leaving messages and reposting. As for the emotional responses, we found that pictures with smiles achieve significant results in guiding the evocation of positive emotions, which can be effectively embodied by people's behavior, such as positive participation and feedback. The relevant literature on cognitive psychology has also suggested that image-intensive types of information provide more complete information factors for people [73,74]. Therefore, when people read information, the repeated prompting of images is more likely to render the information useful in the minds of people. This is because images are like long-term memories; after the brain processes them, they can be successfully stored in the mind. Moreover, by using advertising words or appropriate texts, they can be more effectively evoked in people's minds. Images are the key to the most common successes in the transfer of the culture-creativity image. Images not only convey unique visual experience but also display the characteristics of the target, which are of great importance and irreplaceable significance. In addition, since images have been widely proven to be valuable in building the culture-creativity image [75], brands should be more proactive in using images or films to enhance the culture-creativity image, which will guide people to produce better evaluations or impressions [13]. It is important to use the specific value of images wisely [76] and be willing to use images to attract potential people as well as to build the brand symbol or image, which can promote a positive visual image [77].

Second, depending on the content or exhibition needs, for example, the different characteristics of cultural and creative industries for artists and ordinary people, the use of imagery or sustainability planning for specific topics can also increase the emotional and behavioral participation of community users. This was also pointed out by Gartner: concrete and abstract images in content images affect people's perceptions, emotions, and intentions about brands. Cognition includes knowledge and beliefs. Emotions are usually consistent with the definitions of feelings and attachments. 
After examining the information factors of the images, we found that abstract thematic images, if they are well connected with the brand image, despite being difficult to present, can show remarkable results of message participation compared with pure symbolic images. Therefore, strengthening the construction of themes in building brand image can effectively consolidate people's trust and cognition of the brand content. Hunter (2012), who intended to validate the cultural representations of Okinawa and the Kinmen Islands, conducted a semiotic analysis of network images [78]. Syed-Ahmad et al. (2013) also used images as an index to explain icons and symbols in semiotics and to verify how people define specific culture-creativity images through images [79]. In addition, the discussion of emotional factors indicated that the results of positive "Love" and "Haha" are significant, which demonstrated that interesting content can effectively enhance the characteristics of symbols. Compared with the thematic image, the concrete image can be processed differently in two ways, making its content easier to achieve resonance with people. As mentioned in the literature, images are characterized by the use of rich text to arouse attraction and pleasure in people [80]. People's perception of the content can be triggered not only by cognition and motivation [81] but also through indirect experience. Therefore, the symbols or visual elements in an image can in fact help change people's perception of the brand [82].

Finally, the results of the study clearly showed that the images of high frequency are mainly consistent with the brand name (Huashan or Pier-2), art, design, and other images. This means that whether it is an "ordinary people" positioning or an "artist" positioning, the contents that comply with the corresponding image can easily attract the attention and recognition of people. As for the ambiguous and unclear content, even with exquisite image designs, it is difficult to achieve interactive feedback from most fans, which can also be used as an important reference for the operation of content sustainable development. In general, the purpose of content sustainable development is to establish brand identity and the loyalty of people, which has a positive impact on brand identity. Therefore, according to the framework of social media research [33], this study verified image information in the cultural and creative social platform and explained the interaction between social information and people based on the effectiveness of people's participation. Therefore, this study considered that content sustainable development can be used as a medium to stimulate good communication between people and the brand by displaying creations with either "artist" or "ordinary people" positioning. The key role of the textual posts and the impact of the culture-creativity image should not be underestimated $[83,84]$, especially content participation and people's preferences in relation to the content, which have the most significant impact [85].

This study applied social media content discovery technology to the sustainable development of cultural and creative image management and editing and produced the following recommendations.

First, the key positioning of the brand needs to be clarified; it cannot be ambiguous or uncertain [86]. The use of brand spirit or brand symbols as abstract presentation of thematic categories, supplemented by symbolic brand symbols, can highlight the relevant product or activity characteristics and increase the interest in and variety of the content.

Second, the collocation of pictures and text showed clear and significant results in this study. They affect the positive emotions and behavioral feedback of people. Therefore, in terms of the content sustainable development of brands, if the constant activation of people's relationship or interaction with the content is an aim, the presentation power of the combination of image and text should not be neglected [87].

Third, in regards to concrete symbols in images, such as the smiles of faces, apart from evoking positive emotions, concrete symbols also effectively elicit behavioral participation and encouragement; this effect is more obvious when compared with the effect of objects or images without smiles. The image dialogue for content sustainable development is also one of the special symbols that can be utilized well. 


\subsection{Academic and Practical Contributions}

In terms of the academic contribution, first, this study is different from other types of brand research in the literature, as this study focused only on non-profit cultural and creative brands, collecting posted content, people's behavior, and emotional data for analysis. By comparing social media content from the perspective of the "artist" positioning with that from the "ordinary people" positioning, the differences in image in publication are understood. In summary, images combined with text can achieve the recognition and interaction in content sustainable development more successfully.

Second, this study explored the relationships among information, people's emotions, and behaviors within the framework of the simplest and most understandable behavioral model. Although existing studies have enriched our imagination of people's behavior $[87,88]$, with regard to the constant changes in social media, this study further conducted an interactive discussion of social information quality, people's emotion (Love, Haha, Wow, Sorry, Anger), and people's behavior (Likes, Comments, Shares), which explained the relationship of these three factors on fan pages.

Third, the information orientation of images has a direct impact on social content sustainable development. This study discussed how to transform the content and enhance people's awareness and emotions as well as people's participation to achieve a more effective social dialogue. This study also considered that this framework will effectively examine people's participation in the social media of cultural and creative institutes and can serve as a practical reference for social content sustainable development.

In terms of practical contributions, the findings are as follows: first, the format of most information on fan pages is based on the emotional response of "Love" and "Haha", which means that we can use pure and positive emotions to construct the image context of cultural creations and enhance the positive behavior response and brand identity among people. Therefore, to validate the cultural creations discussed in this study, it is suggested to adopt positive emotions to avoid the blurred or ambiguous information interpretation caused by sad or angry emotions. In addition, it is also suggested to use emotional factors in content sustainable development wisely, which can introduce more positive recognition and interaction for the cultural and creative brands.

Second, in addition to understanding the social interaction of cultural creations, the results of this study specifically validated how to reduce information factor barriers and produce better relations with people. People's behavior interacts with the information presented on social media. People perceiving that they are receiving information without obstacles means, that the information is successfully achieving its informative or emotional goals, which will generate positive participation. Planning the information based on how it is positioned for people is important, which can not only avoid the provision of defective information but also reduce ineffective interaction or content sustainable development.

Third, this study also proposed a conceptual framework to explain how public participation differs in relation to different forms of information. Text and images have the same content orientation, but images provide more informative and emotional incentives to guide people, thus implying that the form of information is the key to how people receive information. Thus, cultural and creative institutes should pay more attention to the graphic design of the content in social media.

Fourth, this study found that in terms of content sustainable development, the information on cultural and creative social media affects people and produces positive content sustainable development. Brand identity can stimulate people to share content proactively; the stronger the sense of identity or pleasure one feels in relation to the brand, the easier the interaction will be. In addition to making good use of their own popularity, brand pages should also manage the quality and quantity of the posts with great care. They should carefully select the most appropriate forms of information according to the content characteristics and strive for content professionalism and richness. In addition, they should enable people to obtain useful and feasible information. It is also important to avoid excessive official propaganda, which may create the dilemma of running social networking platforms without the ability to communicate with people via the content. The model of this study provided more complete and 
helpful concepts regarding the culture-creativity image through a variety of factors. Through social media content analysis, this study aims to reconsider the previously excluded factors and provide a more complete reference for follow-up studies on the culture-creativity image.

\subsection{Limitations of the Research and Suggestions}

First, the concept of the culture-creativity image is quite complex [89,90]. We cannot simply define it at the level of activity or content, because an incomprehensive definition can easily lead to a lack of social, cultural, and historical thinking and judgment [91]. For example, at the current stage, most of the surveys on the integrity of the culture-creativity image have been conducted from the perspective of traditional tourism $[92,93]$ or the overall performance of the culture-creativity image $[40,94]$. In recent years, more research has focused on the content theory; thus, there are abundant achievements in text exploration and the processing of social media content [95]. Based on our results, we can continue to expand the different types of social content, attributes, and relationships and wisely include further different contents in the analysis [96]. In the future, adding multiplex technology can also be considered to enhance analysis. Although many users use the same information, post recommendations are made using artificial intelligence technologies like neural networks. Even for the same post, different types of users' needs can still be met according to their post reading habits.

Second, cultural and creative industries have always been considered as the best means for affirming social practice; they also produce the value and structure of the local culture through the provision of content. Grzesiak (2018) asserted that cultural creation is constructed by people's participation, so it will accumulate over time. Therefore, to understand the culture-creativity image, we have to shift from traditional methods to consider more holistic aspects for discussion [97]. Perhaps based on a more comprehensive approach and sociocultural factors, a conceptual framework conforming to the culture-creativity image can be proposed [24,98]. In the future, we may start with different types of cultural institutions with different brand positioning, such as including other types of cultural or creative institutions for analysis. We may further compare the needs of local or global people in relation to information perception, with the purpose of meeting the needs of people in more countries with different cultural backgrounds and effectively enhancing the use value of social content sustainable development.

Funding: This study was funded by the [Ministry of Science and Technology—Digital Humanities Program] grant number (0610234).

Conflicts of Interest: The author declared no conflicts of interest. 


\section{Appendix A Measurement and Item}

Table A1. Pearson correlation analysis.

\begin{tabular}{|c|c|c|c|c|c|c|c|c|}
\hline \multirow{3}{*}{ Participation Classification } & \multicolumn{4}{|c|}{ The Artist Positioning Brands } & \multicolumn{4}{|c|}{ The Ordinary People Positioning Brands } \\
\hline & \multicolumn{2}{|c|}{ Abstract Factor (AF) } & \multicolumn{2}{|c|}{ Concrete Factor (CF) } & \multicolumn{2}{|c|}{ Abstract Factor (AF) } & \multicolumn{2}{|c|}{ Concrete Factor (CF) } \\
\hline & Pearson's $\mathbf{r}$ & Sig. & Pearson's r & Sig. & Pearson's $\mathbf{r}$ & Sig. & Pearson's r & Sig. \\
\hline Behavioral participation (BP) & $-0.078^{* *}$ & 0.000 & -0.021 & 0.187 & $-0.079^{* *}$ & 0.000 & $-0.080^{* *}$ & 0.000 \\
\hline Likes & $-0.093^{* *}$ & 0.000 & -0.017 & 0.274 & $-0.089 * *$ & 0.000 & $-0.089 * *$ & 0.000 \\
\hline Comments & $0.031 *$ & 0.048 & $-0.043^{* *}$ & 0.007 & 0.004 & 0.752 & 0.008 & 0.571 \\
\hline Shares & -0.012 & 0.433 & -0.014 & 0.367 & $0.039 * *$ & 0.004 & $0.027^{*}$ & 0.043 \\
\hline Emotional participation (EP) & -0.013 & 0.411 & -0.018 & 0.244 & $0.058^{* *}$ & 0.000 & $0.068^{* *}$ & 0.000 \\
\hline Love & 0.004 & 0.810 & -0.012 & 0.437 & $0.078 * *$ & 0.000 & $0.095^{* *}$ & 0.000 \\
\hline Haha & -0.022 & 0.156 & -0.014 & 0.383 & $0.035^{* *}$ & 0.009 & $0.040^{* *}$ & 0.003 \\
\hline Wow & -0.013 & 0.395 & -0.019 & 0.226 & 0.026 & 0.059 & $0.033 *$ & 0.016 \\
\hline Sorry & -0.015 & 0.328 & 0.004 & 0.817 & 0.007 & 0.619 & 0.010 & 0.449 \\
\hline Anger & 0.008 & 0.611 & 0.003 & 0.830 & 0.007 & 0.599 & -0.005 & 0.734 \\
\hline
\end{tabular}

Table A2. Linear regression coefficient of determination and beta (Abstract factor and Concrete factor1).

\begin{tabular}{|c|c|c|c|c|c|c|c|c|c|c|c|c|c|c|}
\hline \multirow[b]{2}{*}{ Participation Classification } & \multicolumn{7}{|c|}{ The Artist Positioning Brands } & \multicolumn{7}{|c|}{ The Ordinary People Positioning Brands } \\
\hline & B & SD & Beta & $\mathbf{T}$ & Sig. & $\begin{array}{c}\text { Sig. F } \\
\text { Change }\end{array}$ & Durbin-Watson & B & SD & Beta & $\mathbf{T}$ & Sig. & $\begin{array}{c}\text { Sig. F } \\
\text { Chang-e }\end{array}$ & Durbin-Watson \\
\hline \multicolumn{15}{|c|}{ Abstract factor (AF) } \\
\hline Emotional participation (EP) & -0.203 & 0.247 & -0.013 & -0.822 & 0.411 & 0.411 & 1.955 & 1.057 & 0.246 & 0.058 & 4.293 & 0.000 & 0.000 & 1.830 \\
\hline Behavioral participation (BP) & -25.711 & 5.139 & -0.078 & -5.004 & 0.000 & 0.000 & 1.645 & -108.207 & 18.355 & -0.079 & -5.895 & 0.000 & 0.000 & 1.761 \\
\hline \multicolumn{15}{|c|}{ Concrete factor (CF) } \\
\hline Emotional participation (EP) & -0.620 & 0.532 & -0.018 & -1.164 & 0.244 & 0.244 & 1.956 & 1.598 & 0.316 & 0.068 & 5.058 & 0.000 & 0.000 & 1.835 \\
\hline Behavioral participation (BP) & -14.656 & 11.099 & -0.021 & -1.321 & 0.187 & 0.187 & 1.630 & -140.015 & 23.561 & -0.080 & -5.943 & 0.000 & 0.000 & 1.762 \\
\hline
\end{tabular}


Table A3. Linear regression coefficient of determination and beta (Abstract factor and Concrete factor2).

\begin{tabular}{|c|c|c|c|c|c|c|c|c|c|c|c|c|c|c|}
\hline \multirow[b]{2}{*}{ Participation Classification } & \multicolumn{7}{|c|}{ The Artist Positioning Brands } & \multicolumn{7}{|c|}{ The Ordinary People Positioning Brands } \\
\hline & B & SD & Beta & $\mathrm{T}$ & Sig. & $\begin{array}{l}\text { Sig. F } \\
\text { Change }\end{array}$ & Durbin-Watson & B & SD & Beta & $\mathbf{T}$ & Sig. & $\begin{array}{l}\text { Sig. F } \\
\text { Change }\end{array}$ & Durbin-Watson \\
\hline \multicolumn{15}{|c|}{ Abstract factor (AF) } \\
\hline Likes & -25.735 & 4.337 & -0.093 & -5.934 & 0.000 & 0.000 & 1.588 & -113.025 & 17.105 & -0.089 & -6.608 & 0.000 & 0.000 & 1.748 \\
\hline Comments & 0.817 & 0.413 & 0.031 & 1.978 & 0.048 & 0.048 & 1.998 & 0.098 & 0.309 & 0.004 & 0.316 & 0.752 & 0.752 & 1.844 \\
\hline Shares & -0.794 & 1.012 & -0.012 & -0.784 & 0.433 & 0.433 & 1.923 & 4.720 & 1.654 & 0.039 & 2.853 & 0.004 & 0.004 & 1.913 \\
\hline Love & 0.024 & 0.098 & -0.004 & 0.241 & 0.810 & 0.810 & 1.897 & 0.480 & 0.082 & 0.078 & 5.819 & 0.000 & 0.000 & 1.701 \\
\hline Haha & -0.124 & 0.087 & -0.022 & -1.418 & 0.156 & 0.156 & 2.001 & 0.420 & 0.161 & 0.035 & 2.604 & 0.009 & 0.009 & 2.000 \\
\hline Wow & -0.097 & 0.114 & -0.013 & -0.851 & 0.395 & 0.395 & 1.982 & 0.127 & 0.067 & 0.026 & 1.889 & 0.059 & 0.059 & 1.871 \\
\hline Sorry & -0.008 & 0.008 & -0.015 & -0.978 & 0.328 & 0.328 & 1.940 & 0.018 & 0.036 & 0.007 & 0.498 & 0.619 & 0.619 & 1.997 \\
\hline Anger & 0.002 & 0.003 & 0.008 & 0.509 & 0.611 & 0.611 & 2.008 & 0.012 & 0.023 & 0.007 & 0.526 & 0.599 & 0.599 & 1.985 \\
\hline \multicolumn{15}{|c|}{ Concrete factor (CF) } \\
\hline Likes & -10.271 & 9.380 & -0.017 & -1.095 & 0.274 & 0.274 & 1.568 & -144.537 & 21.957 & -0.089 & -6.583 & 0.000 & 0.000 & 1.748 \\
\hline Comments & -2.418 & 0.890 & -0.043 & -2.718 & 0.007 & 0.007 & 2.001 & 0.225 & 0.397 & 0.008 & 0.566 & 0.571 & 0.571 & 1.843 \\
\hline Shares & -1.968 & 2.180 & -0.014 & -0.903 & 0.367 & 0.367 & 1.923 & 4.297 & 2.124 & 0.027 & 2.023 & 0.043 & 0.043 & 1.915 \\
\hline Love & -0.164 & 0.211 & -0.012 & -0.777 & 0.437 & 0.437 & 1.897 & 0.747 & 0.106 & 0.095 & 7.070 & 0.000 & 0.000 & 1.705 \\
\hline Haha & -0.164 & 0.188 & -0.014 & -0.872 & 0.383 & 0.383 & 2.002 & 0.617 & 0.207 & 0.040 & 2.979 & 0.003 & 0.003 & 2.002 \\
\hline Wow & -0.297 & 0.246 & -0.019 & -1.212 & 0.226 & 0.226 & 1.983 & 0.208 & 0.086 & 0.033 & 2.411 & 0.016 & 0.016 & 1.872 \\
\hline Sorry & 0.004 & 0.017 & 0.004 & 0.231 & 0.817 & 0.817 & 1.942 & 0.035 & 0.047 & 0.010 & 0.757 & 0.449 & 0.449 & 1.997 \\
\hline Anger & 0.001 & 0.007 & 0.003 & 0.215 & 0.830 & 0.830 & 2.008 & -0.010 & 0.029 & -0.005 & -0.340 & 0.734 & 0.734 & 1.985 \\
\hline
\end{tabular}




\section{References}

1. Boes, K.; Buhalis, D.; Inversini, A. Conceptualising Smart Tourism Destination Dimensions. In Information and Communication Technologies in Tourism 2015; Springer: Berlin, Germany, 2015; pp. 391-403.

2. Kalampokis, E.; Tambouris, E.; Tarabanis, K. Understanding the predictive power of social media. Int. Res. 2013, 23, 544-559. [CrossRef]

3. Abrahams, A.S.; Jiao, J.; Fan, W.; Wang, G.A.; Zhang, Z. What's buzzing in the blizzard of buzz? Automotive component isolation in social media postings. Decis. Support Syst. 2013, 55, 871-882.

4. He, W.; Zha, S.; Li, L. Social media competitive analysis and text mining: A case study in the pizza industry. Int. J. Inf. Manag. 2013, 33, 464-472. [CrossRef]

5. Fayyad, U.; Piatetsky-Shapiro, G.; Smyth, P. From data mining to knowledge discovery in databases. AI Mag. 1996, 17, 37-53.

6. Filieri, R.; McLeay, F. E-WOM and Accommodation: An Analysis of the Factors That Influence Travelers' Adoption of Information from Online Reviews. J. Travel Res. 2014, 53, 44-57. [CrossRef]

7. Tang, X.; Yang, C.C. Social network integration and analysis using a generalization and probabilistic approach for privacy preservation. Secur. Inform. 2017, 1, 1-14. [CrossRef]

8. Chanana, V.; Ginige, A.; Murugesan, S. Improving information retrieval effectiveness by assigning context to documents. In Proceedings of the 2004 International Symposium on Information and Communication Technologies, Trinity College Dublin, Parma, Italy, 10-13 October 2004; pp. 86-91.

9. Kaplan, A.M.; Haenlein, M. Users of the world, unite! The challenges and opportunities of Social Media. Bus. Horiz. 2010, 53, 59-68.

10. Fletcher, A.; Lee, M.J. Current social media uses and evaluations in American museums. Mus. Manag. Curatorship 2012, 27, 505-521. [CrossRef]

11. Wang, C.Y.; Hsu, M.K. The relationships of destination image, satisfaction, and behavioral intentions: An integrated model. J. Travel Tour. Mark. 2010, 27, 829-843. [CrossRef]

12. Han, J.; Kamber, M.; Pei, J. Data Mining: Concepts and Techniques; Elsevier: Amsterdam, The Netherlands, 2011.

13. Choi, S.; Lehto, X.Y.; Morrison, A.M. Destination image representation on the web: Content analysis of Macau travel related websites. Tour. Manag. 2007, 28, 118-129. [CrossRef]

14. Lee, T.H. A Structural model to examine how destination image, attitude, and motivation affect the future behavior of tourists. Leis. Sci. 2009, 31, 215-236. [CrossRef]

15. Huang, W.J.; Chen, C.C.; Lin, Y.H. Cultural proximity and intention to visit: Destination image of Taiwan as perceived by Mainland Chinese visitors. J. Destin. Mark. Manag. 2013, 2, 176-184. [CrossRef]

16. Govers, R.; Go, F.M.; Kumar, K. Virtual destination image a new measurement approach. Ann. Tour. Res. 2007, 34, 977-997. [CrossRef]

17. Holden, J. Cultural Value and the Crisis of Legitimacy; Demos: London, UK, 2006.

18. Newman, A.; Goulding, A.; Whitehead, C. The consumption of contemporary visual art: Identity formation in late adulthood. Cult. Trends 2012, 21, 29-45. [CrossRef]

19. Blagoeva-Yarkova, Y. The role of local cultural institutions for local sustainable development. The case-study of Bulgaria. Trakia J. Sci. 2012, 10, 42-52.

20. Fanea-Ivanovici, M. Culture as a prerequisite for sustainable development. An investigation into the process of cultural content digitisation in Romania. Sustainability 2018, 10, 1859.

21. Throsby, D. Cultural sustainability. In A Handbook of Cultural Economics; Edward Elgar Publishing: Cheltenham, UK, 2011; pp. 183-186.

22. Mpofu, P. The dearth of culture in sustainable development: The impact of NGOs' agenda and conditionalities on cultural sustainability in Zimbabwe. J. Sustain. Dev. Afr. 2012, 14, 191-205.

23. Gray, J. Show Sold Separately: Promos, Spoilers, and Other Media Paratexts; NYU Press: New York, NY, USA, 2010.

24. Wróblewski, Ł.; Bilińska-Reformat, K.; Grzesiak, M. Sustainable activity of cultural service consumers of social media users-Influence on the brand capital of cultural institutions. Sustainability 2018, 10, 3986. [CrossRef]

25. Buhalis, D.; Foerste, M. SoCoMo marketing for travel and tourism: Empowering co-creation of value. J. Destin. Mark. Manag. 2015, 4, 151-161. [CrossRef]

26. Aaker, D.A. Measuring brand equity across products and markets. Calif. Manag. Rev. 1996, 38, 102-120. [CrossRef] 
27. Cobb-Walgren, C.J.; Ruble, C.A.; Donthu, N. Brand equity, brand preference, and purchase intent. J. Advert. 1995, 24, 25-40. [CrossRef]

28. Kim, H.; Stepchenkova, S. Effect of tourist photographs on attitudes towards destination: Manifest and latent content. Tour. Manag. 2015, 49, 29-41. [CrossRef]

29. Hoffman, D.L.; Novak, T.P. Marketing in hypermedia computer-mediated environments: Conceptual foundations. J. Mark. 1996, 60, 50-68. [CrossRef]

30. Zhang, K.Z.K.; Zhao, S.J.; Cheung, C.M.K.; Lee, M.K.O. Examining the influence of online reviews on consumers' decision-making: A heuristic-systematic model. Decis. Support Syst. 2014, 67, 78-89. [CrossRef]

31. Schau, H.J.; Muñiz, A.M., Jr.; Arnould, E.J. How brand community practices create value. J. Mark. 2009, 73, 30-51. [CrossRef]

32. Hunt, J.D. Image - A Factor in Tourism; National Agricultural Library: Beltsville, MD, USA, 1971.

33. Aral, S.; Dellarocas, C.; Godes, D. Social media and business transformation: A Framework for research. Inf. Syst. Res. 2013, 24, 3-13. [CrossRef]

34. Stieglitz, S.; Dang-Xuan, L.; Bruns, A.; Neuberger, C. Social media analytics. Bus. Inf. Syst. Eng. 2014, 6, 89-96. [CrossRef]

35. Pentina, I.; Zhang, L.; Basmanova, O. Antecedents and consequences of trust in a social media brand: A cross-cultural study of Twitter. Comput. Hum. Behav. 2013, 29, 1546-1555. [CrossRef]

36. Karl, M.; Reintinger, C.; Schmude, J. Reject or select: Mapping destination choice. Ann. Tour. Res. 2015, 54, 48-64. [CrossRef]

37. Woodside, A.G.; Lysonski, S. A general model of traveler destination choice. J. Travel Res. 1989, $27,8-14$. [CrossRef]

38. Cian, L. How to measure brand image: A reasoned review. Mark. Rev. 2011, 11, 165-187. [CrossRef]

39. Gartner, W.C. Image formation process. J. Travel Tour. Mark. 1994, 2, 191-216. [CrossRef]

40. Gallarza, M.G.; Saura, I.G.; García, H.C. Destination image: Towards a conceptual framework. Ann. Tour. Res. 2002, 29, 56-78. [CrossRef]

41. Snepenger, D.; Snepenger, M.; Dalbey, M.; Wessol, A. Meanings and consumption characteristics of places at a tourism destination. J. Travel Res. 2007, 45, 310-321. [CrossRef]

42. Huang, Y.; Basu, C.; Hsu, M.K. Exploring motivations of travel knowledge sharing on social network sites: An empirical investigation of U.S. college students. J. Hosp. Mark. Manag. 2010, 19, 717-734. [CrossRef]

43. Kahn, B.K.; Strong, D.M.; Wang, R.Y. Information Quality Benchmarks: Product and Service Performance. Commun. ACM 2002, 45, 184-192. [CrossRef]

44. Wang, R.Y. Beyond accuracy: What data quality means to data consumers. J. Manag. Inf. Syst. 1996, 12, 5-34. [CrossRef]

45. Agarwal, R.; Karahanna, E. Time flies when you're having fun: Cognitive absorption and beliefs about information technology usage. MIS Q. Manag. Inf. Syst. 2000, 24, 665-694. [CrossRef]

46. Klein, B.D. When do users detect information quality problems on the World Wide Web. In Proceedings of the 8th Americas Conference on Information Systems, Dallas, TX, USA, 7-9 August 2002; pp. 1101-1103.

47. Knight, S.A.; Burn, J. Developing a framework for assessing information quality on the World Wide Web. Inf. Sci. 2005, 8, 159-172.

48. Emamjome, F.F.; Rabaa'i, A.A.; Gable, G.G.; Bandara, W. Information quality in social media: A conceptual model. In Proceedings of the Pacific Asia Conference on Information Systems, PACIS 2013, Jeju Island, Korea, 18-22 June 2013.

49. Dellarocas, $\mathrm{C}$. The digitization of word of mouth: Promise and challenges of online feedback mechanisms. Manag. Sci. 2003, 49, 1407-1424. [CrossRef]

50. Lee, K.Y.; Yang, S.B. The role of online product reviews on information adoption of new product development professionals. Int. Res. 2015, 25, 435-452. [CrossRef]

51. Prayag, G. Tourists' evaluations of destination image, satisfaction, and future behavioral intentions-the case of mauritius. J. Travel Tour. Mark. 2009, 26, 836-853. [CrossRef]

52. Tseng, C.; Wu, B.; Morrison, A.M.; Zhang, J.; Chen, Y. Travel blogs on China as a destination image formation agent: A qualitative analysis using Leximancer. Tour. Manag. 2015, 46, 347-358. [CrossRef]

53. Gunn, C.A. Vacationscape: Designing Tourist Regions; Van Nostrand Reinhold: New York, NY, USA, 1988.

54. Pike, S. Destination image analysis-A review of 142 papers from 1973 to 2000. Tour. Manag. 2002, 23, 541-549. [CrossRef] 
55. Parent, M.; Plangger, K.; Bal, A. The new WTP: Willingness to participate. Bus. Horiz. 2011, 54, $219-229$. [CrossRef]

56. Katona, Z.; Zubcsek, P.P.; Sarvary, M. Network effects and personal influences: The diffusion of an online social network. J. Mark. Res. 2011, 48, 425-443. [CrossRef]

57. LaRose, R.; Eastin, M.S. A social cognitive theory of Internet uses and gratifications: Toward a new model of media attendance. J. Broadcast. Electron. Media 2004, 48, 358-377. [CrossRef]

58. Grubb, E.L.; Grathwohl, H.L. Consumer self-concept, symbolism and market behavior: A theoretical approach. J. Mark. 1967, 31, 22-27. [CrossRef]

59. Bower, G.H. Mood and memory. Am. Psychol. 1981, 36, 129. [CrossRef]

60. Clore, G.L.; Gasper, K.; Garvin, E. Affect as information. In Handbook of Affect and Social Cognition; Lawrence Erlbaum Associates: Mahwah, NJ, USA, 2001; pp. 121-144.

61. Schwarz, N.; Clore, G.L. Mood as information: 20 years later. Psychol. Inq. 2003, 14, 296-303.

62. Goldberg, M.E.; Gorn, G.J. Happy and sad TV programs: How they affect reactions to commercials. J. Consum. Res. 1987, 14, 387-403. [CrossRef]

63. Siemer, M. Mood-congruent cognitions constitute mood experience. Emotion 2005, 5, 296. [CrossRef]

64. Sirgy, M.J. Self-concept in consumer behavior: A critical review. J. Consum. Res. 1982, 9, 287-300. [CrossRef]

65. Wallace, E.; Buil, I.; de Chernatony, L.; Hogan, M. Who "likes" you ... and why? A typology of Facebook fans: From "fan"-atics and self-expressives to utilitarians and authentics. J. Advert. Res. 2014, 54, 92-109. [CrossRef]

66. Pham, M.T.; Avnet, T. Contingent reliance on the affect heuristic as a function of regulatory focus. Organ. Behav. Hum. Decis. Process. 2009, 108, 267-278. [CrossRef]

67. Brodie, R.J.; Hollebeek, L.D.; Jurić, B.; Ilić, A. Customer engagement: Conceptual domain, fundamental propositions, and implications for research. J. Serv. Res. 2011, 14, 252-271. [CrossRef]

68. Tsai, W.-H.S.; Men, L.R. Motivations and antecedents of consumer engagement with brand pages on social networking sites. J. Interact. Advert. 2013, 13, 76-87. [CrossRef]

69. Cvijikj, I.P.; Michahelles, F. A case study of the effects of moderator posts within a Facebook brand page. In International Conference on Social Informatics; Springer: Berlin, Germany, 2011.

70. Goorha, S.; Ungar, L. Discovery of significant emerging trends. In Proceedings of the 16th ACM SIGKDD International Conference on Knowledge Discovery and Data Mining, Washington, DC, USA, 25-28 July 2010.

71. Lewis, K.; Kaufman, J.; Gonzalez, M.; Wimmer, A.; Christakis, N. Tastes, ties, and time: A new social network dataset using Facebook.com. Soc. Netw. 2008, 30, 330-342. [CrossRef]

72. Teevan, J.; Ramage, D.; Morris, M.R. \# TwitterSearch: A comparison of microblog search and web search. In Proceedings of the Fourth ACM International Conference on Web Search and Data Mining, Hong Kong, China, 9-12 February 2011.

73. LaBarbera, P.A.; Weingard, P.; Yorkston, E.A. Matching the message to the mind: Advertising imagery and consumer processing styles. J. Advert. Res. 1998, 38, 29-30.

74. Unnava, H.R.; Burnkrant, R.E. An imagery-processing view of the role of pictures in print advertisements. J. Mark. Res. 1991, 28, 226-231. [CrossRef]

75. MacKay, K.J.; Fesenmaier, D.R. Pictorial element of destination in image formation. Ann. Tour. Res. 1997, 24, 537-565. [CrossRef]

76. Hunter, W.C. A typology of photographic representations for tourism: Depictions of groomed spaces. Tour. Manag. 2008, 29, 354-365. [CrossRef]

77. Ye, H.; Tussyadiah, I.P. Destination visual image and expectation of experiences. J. Travel Tour. Mark. 2011, 28, 129-144. [CrossRef]

78. Hunter, W.C. The good souvenir: Representations of Okinawa and Kinmen Islands in Asia. J. Sustain. Tour. 2012, 20, 81-99. [CrossRef]

79. Syed-Ahmad, S.F.; Musa, G.; Klobas, J.E.; Murphy, J. Audience Response to Travel Photos and Arab Destination Image. J. Travel Tour. Mark. 2013, 30, 161-164. [CrossRef]

80. Molina, A.; Esteban, A. Tourism Brochures. Usefulness and Image. Ann. Tour. Res. 2006, 33, $1036-1056$. [CrossRef]

81. Rajaguru, R. Motion Picture-Induced Visual, Vocal and Celebrity Effects on Tourism Motivation: Stimulus Organism Response Model. Asia Pac. J. Tour. Res. 2014, 19, 375-388. [CrossRef] 
82. Stepchenkova, S.; Zhan, F. Visual destination images of Peru: Comparative content analysis of DMO and user-generated photography. Tour. Manag. 2013, 36, 590-601. [CrossRef]

83. Clark, M.; Melancon, J. The influence of social media investment on relational outcomes: A relationship marketing perspective. Int. J. Mark. Stud. 2013, 5, 132. [CrossRef]

84. Goh, K.Y.; Heng, C.S.; Lin, Z. Social media brand community and consumer behavior: Quantifying the relative impact of user- and marketer-generated content. Inf. Syst. Res. 2013, 24, 88-107. [CrossRef]

85. Larson, K.; Watson, R. The Value of Social Media: Toward Measuring Social Media Strategies; ICIS 2011 Proceedings: Shanghai, China, 2011.

86. Campbell, D.E.; Wells, J.D.; Valacich, J.S. Breaking the ice in B2C relationships: Understanding pre-adoption e-commerce attraction. Inf. Syst. Res. 2013, 24, 219-238. [CrossRef]

87. Nambisan, S.; Baron, R.A. Interactions in virtual customer environments: Implications for product support and customer relationship management. J. Interact. Mark. 2007, 21, 42-62. [CrossRef]

88. Kohler, T.; Fueller, J.; Matzler, K.; Stieger, D. Co-creation in virtual worlds: The design of the user experience. MIS Q. 2011, 35, 773-788. [CrossRef]

89. Soini, K.; Birkeland, I. Exploring the scientific discourse on cultural sustainability. Geoforum 2014, 51, $213-223$. [CrossRef]

90. Killian, G.; McManus, K. A marketing communications approach for the digital era: Managerial guidelines for social media integration. Bus. Horiz. 2015, 58, 539-549. [CrossRef]

91. Mazurek-Lopacińska, K.; Sobocińska, M. Marketing communication in the light of challenges brought about by virtualisation and interactivity. Econ. Bus. Rev. 2016, 2, 65-76. [CrossRef]

92. Cave, J.; Ryan, C.; Panakera, C. Cultural tourism product: Pacific Island migrant perspectives in New Zealand. J. Travel Res. 2007, 45, 435-443. [CrossRef]

93. Ryan, C.; Cave, J. Structuring destination image: A qualitative approach. J. Travel Res. 2005, 44, 143-150. [CrossRef]

94. Saraniemi, S.; Kylänen, M. Problematizing the concept of tourism destination: An analysis of different theoretical approaches. J. Travel Res. 2011, 50, 133-143. [CrossRef]

95. He, J.; Liu, H.; Xiong, H. SocoTraveler: Travel-package recommendations leveraging social influence of different relationship types. Inf. Manag. 2016, 53, 934-950. [CrossRef]

96. Shao, G. Understanding the appeal of user-generated media: A uses and gratification perspective. Int. Res. 2009, 19, 7-25. [CrossRef]

97. Grzesiak, M. Personal Brand Creation in the Digital Age: Theory, Research and Practice; Springer International Publishing AG: Basel, Switzerland, 2018; pp. 1-185.

98. Smith, P.R.; Zook, Z. Marketing Communications: Integrating Offline and Online with Social Media; Kogan Page: London, UK, 2011.

(C) 2019 by the author. Licensee MDPI, Basel, Switzerland. This article is an open access article distributed under the terms and conditions of the Creative Commons Attribution (CC BY) license (http://creativecommons.org/licenses/by/4.0/). 